\title{
Analysis of main causes of defects of multi- storey reinforced concrete frame buildings
}

\author{
Vladimir Yamov ${ }^{1}$, and Zoya Belyaeva ${ }^{2, *}$ \\ ${ }^{1}$ Ural Federal University, Institute of Civil Engineering and Architecture, Department of Industrial, \\ civil construction and real estate expertise, 620002 Ekaterinburg, Russia \\ ${ }^{2}$ Ural Federal University, Institute of Civil Engineering and Architecture, Department of Building \\ structures and soil mechanics, 620002 Ekaterinburg, Russia
}

\begin{abstract}
Multi-storey reinforced concrete frame buildings are widespread in Russia. Most of these buildings have braced frame system, where the main load-bearing elements are columns, beams and hollow floor slabs, and the spatial rigidity is provided by additional diaphragms, staircase and elevator section. Such buildings are easy to design and build and are quite multifunctional in purpose. The article on the basis of the authors' experience in the survey examines the main defects in such buildings. The causes of typical defects can be divided into objective, technological and operational reasons. Usually, the cause of survey can be structural damage discovered by the building owner that is why often the survey is conducted during the emergency condition, which can be avoided, if inspections and monitoring of the structures technical state are regular. Also there is a necessity of improving the design methods of new buildings and strengthening of existing ones.
\end{abstract}

\section{Introduction}

Multi-storey reinforced concrete buildings of the uniform design are widespread in Russia. Frames of this kind of building are mostly built from precast elements - columns, beams, and slabs (see Fig. 1). The rigidity and stability of the building, as a whole system, is provided by the elements of rigidity - diaphragms, staircase and elevator section, as well as by floor structure, which transmit the arising horizontal forces to the frame and diaphragms. These buildings are simple in design and quite multifunctional in use - they could be used as industrial, office or public buildings.

The most part of this kind of reinforced concrete building was built in the $80 \mathrm{~s}$ and $90 \mathrm{~s}$ of the 20th century. Though the design working life of reinforced concrete structures is more than 50 years a lot of building have defects which significantly reduce its service life.

According to results of surveys of the technical condition of multi-storey reinforced concrete buildings, which were carried out by the staff members Institute of Civil Engineering and Architecture, defects in them are caused by various factors. The analysis of the obtained data allows us to identify the main causes of defects that lead to the

\footnotetext{
*Corresponding author: z.v.beliaeva@,urfu.ru
} 
emergency condition of buildings. These defects can be divided into separate blocks: objective reasons, technological reasons, and operational reasons.

In this paper we will consider main causes of defects in reinforced concrete buildings with precast elements.

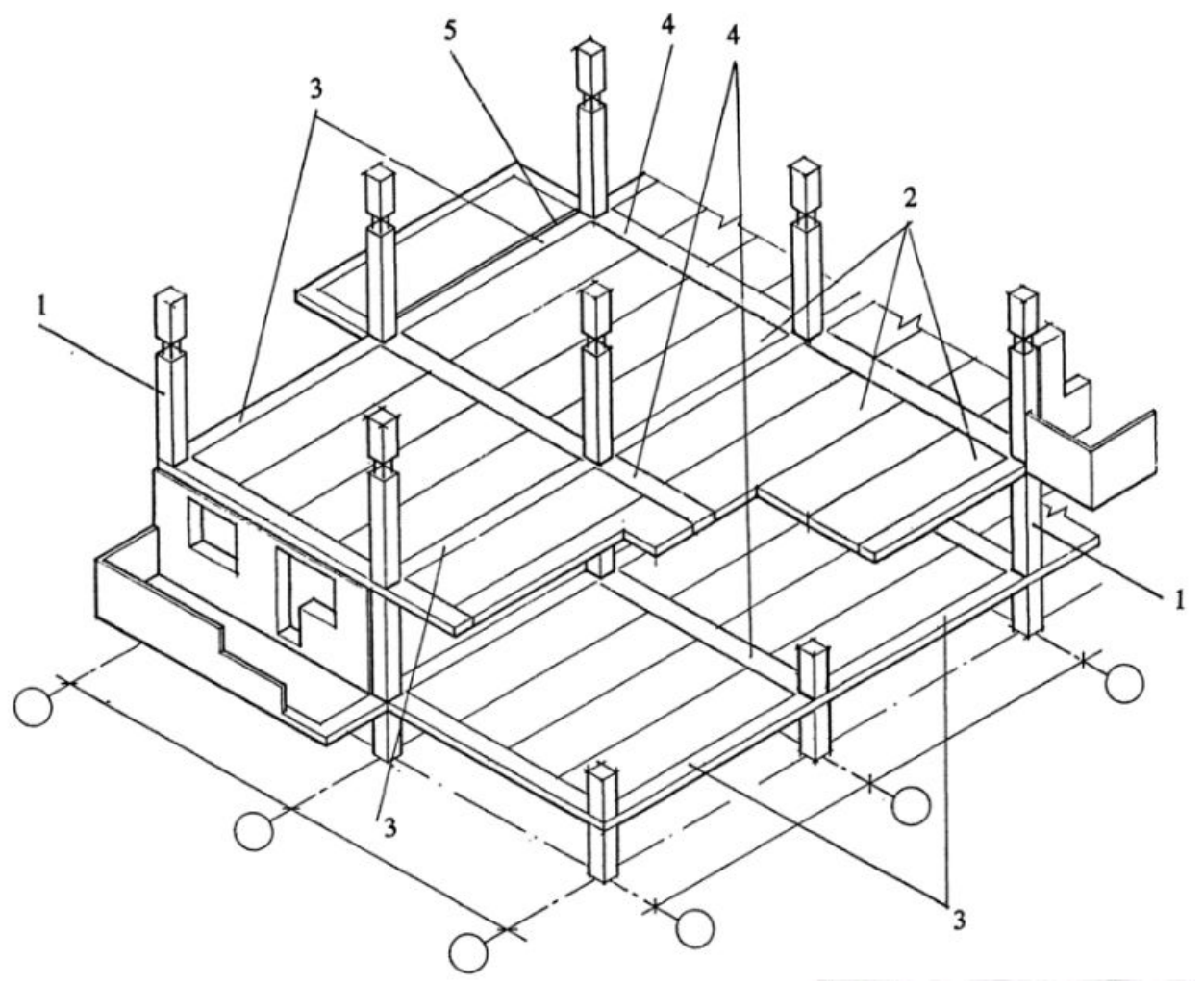

Fig. 1. Schematic diagram of the building frame according to Standard serie 1.020: 1 - column; 2 - hollow core slab; 3 - bracing beam or slab; 4 -bearing beam; 5 - heat isolation

\section{Objective causes}

The objective causes of defects mainly arise from the shortcomings of the standard design (Standard series).

\subsection{The heterogeneous work of the foundation structures}

This fact is the first of the shortcomings of the project (Standard series), in which the foundations are designed in different way: under columns there are post footings, and under the self-supporting external walls and diaphragms of rigidity there are girder foundations. This leads to a significant difference in the values of loads on foundations and load from a column can vary from 100 up to 200 tons when load from an external wall in more than ten times less. The structural width of the girder foundations is not less than $800-1000 \mathrm{~mm}$, because the width of the wall is $640 \mathrm{~mm}$, so the specific pressure on the soil is many times less than from the foundation of the columns, which results in uneven settlement and destruction of the structures joints. 


\subsection{Strong influence of complex engineering-geological conditions}

In Sverdlovsk region local changes in the bearing capacity of soils in the area of the building perimeter could exist. For example, the foundation soil can be presented by eluvial soil of varying degrees of weathering. This fact in conjunction with the above point significantly increases the possibility of uneven settlement.

\subsection{A large number of connections and presence of hidden connections}

Precast reinforced concrete elements (columns, beams, slabs, diaphragms, bracing), require large amounts of welding, as well as wet processes for the homogenization of nodes. Also many of these connections are hidden. For example, fixing the outer walls to the columns is made with the help of flexible metal ties, stored in the joints of masonry walls. In this case quality of connections is difficult to ensure.

\section{Technological causes}

The technological causes are mistakes made during construction.

\subsection{Absence of compliance with erection standards}

Installation of bearing elements with deviation from the design position, which sometimes exceeds the established construction standards tolerances, results in a change in the stress state of the structures. In some cases, girder foundations of walls or walls themselves are partially supported by post foundations of columns, which leads to distortion of the design scheme of foundations and wasn't considered in project.

\subsection{Insufficient rigidity of the building frame}

Non-design position bracing slabs due to inaccurate installation of columns or replacement of bracing slabs on conventional ones with a hand-cut groove for the column and nondesigned or partial anchoring or sometimes complete absence of anchoring between slabs reduces the rigidity of the floor structure.

The reduction of the stiffness of connections between wall diaphragms and columns at due to unreasonably high gaps and grouting of the vertical joints with concrete of low grades, the absence of operational monitoring of welded seams are also reasons of insufficient rigidity of the building frame.

\subsection{Winter construction}

Erection of building structures in the winter time when the wet processes in the grouting leads to change in technology, increase of complexity, and of the cost of construction, and often, for the sake of savings, technologies for summer time are used, which results in the detriment of strength and rigidity.

\subsection{Long-delayed construction}

In cases when the construction of the building is interrupted for 2-3 years or more the building goes into the category of long-delayed construction. In a lot of cases when construction works are resumed a project owner doesn't conduct a survey of technical 
conditions of the constructed part and resumes construction at his own risk. During the break in construction, the building structures are often not preserved and therefore undergo changes: freezing of the soil under foundations, deformation of foundations, flooding of basements, reduction of physical and technical characteristics of materials and structures, etc. With the resumption of construction appeared and unfixed defects adversely affect properties of the building structures.

\section{Operational causes}

Poor and improper building maintenance will definitely cause more damages and costly repair works if left unattended. In some cases, maintenance of building is performed only in the mechanical and electrical systems in the buildings, but bearing structures are left without repairs.

\subsection{Absence of technical service}

Very often buildings owners ignore requirements of technical monitoring of buildings in the part of bearing structures. In many cases there is no proper supervision of the serviceable condition of structures, the correct operation of engineering systems of the building with marks in logs of supervision and in technical passports. Regular maintenance and remedial repairs to maintain the buildings in good condition are ignored.

\subsection{Change of the hydrogeological conditions on the site}

In the process of long-term operation of the building the level of groundwater increases due to leaks from building services systems, construction activities near the building, failure of drainage systems. Mentioned factors modify the influence of groundwater on building structures, and can also cause a suffusion of soils with repackaging of the soil skeleton and the additional unequal settlement of the building.

\subsection{The lack of response to the force majeure situations}

Flooding of basements, cracking and deformations in load-bearing structures, caused by uneven settlement of the foundations, or related to the overloading of individual parts of buildings leased for other purposes, the constant leaks from the roof and dysfunction of the drainage elements in the ground level (perimeter pavement, perimeter drainage channels). Some buildings continue to be in operation with flooded basements and foundations.

\section{Discussion}

An extension of the hospital of war veterans [1] and the building of the "Uraltel" in Yekaterinburg are typical examples of buildings with precast RC structures. The building of the hospital was built with temporary pauses in 1-2 years. The construction lasted from 1993 to 2001. During breaks in construction building structures were not preserved. Both design and construction errors listed above were made in full. The building received uneven settlement, which resulted in the appearance of cracks and deflections of beams (see Fig. 2). As it became clear in the course of technical inspection, the situation was considerably aggravated by deviation from the project in the construction of foundations (see Fig. 3).

Untimely identified and unrepaired defects of building elements often develop into serious violations. Their consequences, in addition to significant material costs associated 
with the restoration of the operational properties of structures, lead to social and environmental damage. Therefore, it is important to properly and timely assess the condition of structures and equipment of buildings, to predict the possible development of defects and to develop measures to stabilize or eliminate them. It is necessary to have an understanding of the mechanism of destruction and wear of structural elements in the process of operation, the mechanism of the influence of environmental factors operating on the construction of the structure [2-6].

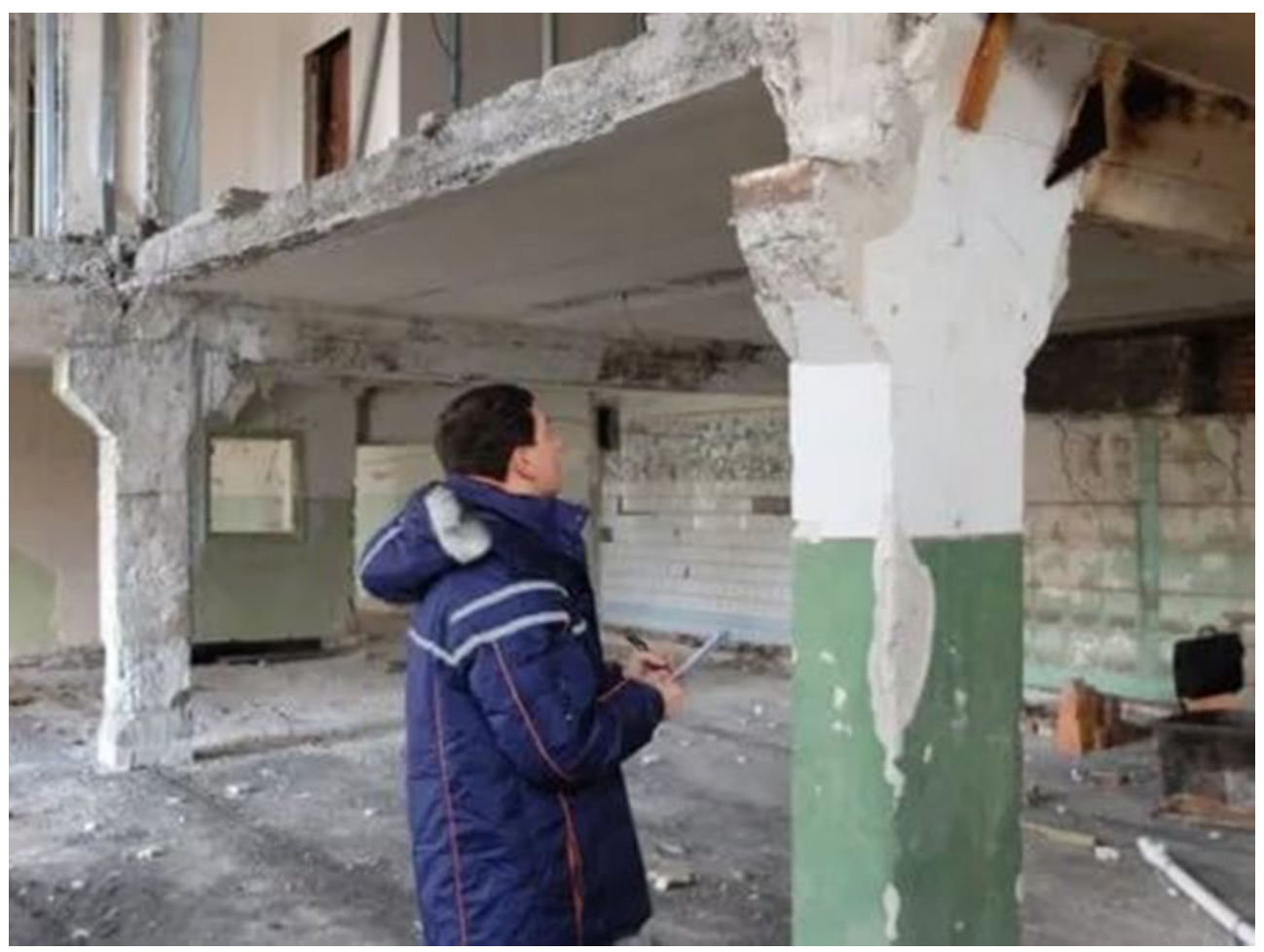

Fig. 2. An example of ignoring the restorative repairs at the results of the technical monitoring: differential settlement of foundations was the cause of the deflections of beams and slabs

\section{Conclusions}

Usually, the cause of survey can be structural damage discovered by the building owner that is why often the survey is conducted during the emergency condition, which can be avoided, if inspections and monitoring of the structures technical state are regular. Also there is a necessity of improving the design methods of new buildings and strengthening of existing ones. 


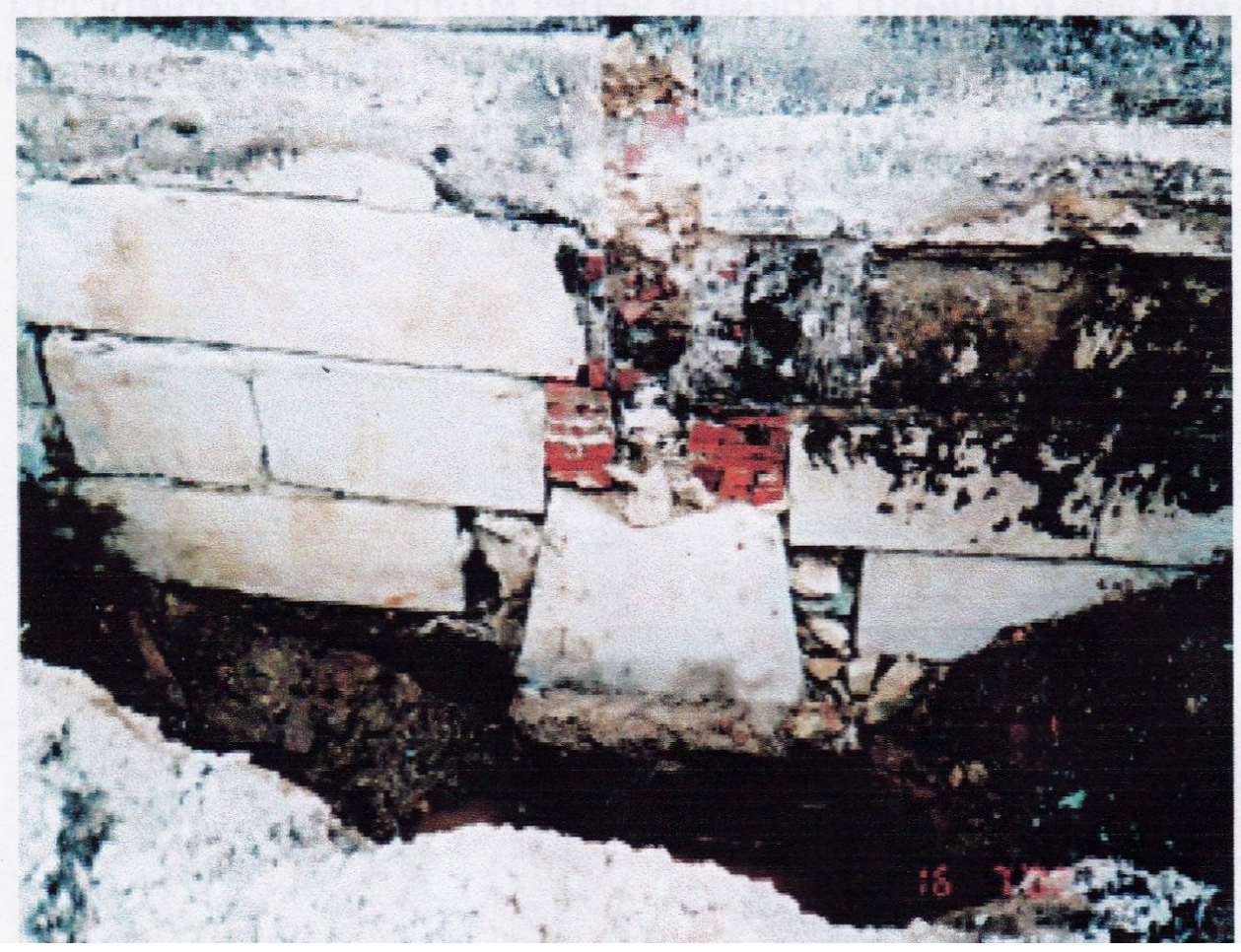

Fig. 3. Non-design combination of girder and post foundations

\section{References}

1. V. I. Yamov, Technical report on the results of technical inspection of the building attached to the hospital of war veterans and technical solutions for the restoration of the building (Yekaterinburg, 2002)

2. J. Šelih., Journal of Civil Engineering and Management, 16 (2), 306-311 (2010)

3. P. Berkowski, G. Dmochowskib, M. Kosior-Kazberuk, Modern Building Materials, Structures and Techniques, 183-192 (2013)

4. M. Loginova, A. Krapiva, M. Stratonov, V. Kryukov, Technadzor, 10 (107), 383 (2015)

5. V.A. Bekker, A.N. Narushevich, News of universities. Construction, 8, 97-99 (2005)

6. C. Page, P. Murray, Structural Survey, 14 (2), 35-40 (1996) 